\title{
Synergistic activity of agents targeting growth factor receptors, CDKs and downstream signaling molecules in a panel of pancreatic cancer cell lines and the identification of antagonistic combinations: Implications for future clinical trials in pancreatic cancer
}

\author{
TANZEEL KHAN $^{1}$, ALAN M. SEDDON ${ }^{1}$, ANGUS G. DALGLEISH ${ }^{2}$, SAID KHELWATTY $^{1}$, \\ NIKOLAOS IOANNOU $^{3}$, SATVINDER MUDAN ${ }^{2}$ and HELMOUT MODJTAHEDI ${ }^{1}$ \\ ${ }^{1}$ School of Life Science, Pharmacy and Chemistry, Kingston University London, \\ Surrey KT1 2EE; ${ }^{2}$ St George's Hospital, University of London, London SW17 0QT; \\ ${ }^{3}$ School of Cancer and Pharmaceutical Sciences, King's College London, London SE5 9NT, UK
}

Received July 15, 2020; Accepted October 6, 2020

DOI: $10.3892 /$ or.2020.7822

\begin{abstract}
Pancreatic cancer is one of the most aggressive, heterogeneous and fatal type of human cancers for which more effective therapeutic agents are urgently needed. Here, we investigated the sensitivity of a panel of seven human pancreatic cancer cell lines (HPCCLs) to treatment with various tyrosine kinase inhibitors (TKIs), cyclin-dependent kinase (CDK) inhibitors, an inhibitor of STAT3 stattic, and a cytotoxic agent gemcitabine both as single agents and in combination. The membranous expression of various receptors and the effect of selected agents on cell cycle distribution, cell signaling pathways and migration was determined using flow cytometry, western blot analysis and scratch wound healing assays, respectively. While the expression of both HER-3 and HER-4 was low or negative, the expression of EGFR and HER2 was high or intermediate in all HPCCLs. Of all the agents examined, the CDK1/2/5/9 inhibitor, dinacicilib, was the most potent agent which inhibited the proliferation of all seven HPCCLs
\end{abstract}

Correspondence to: Professor Helmout Modjtahedi, School of Life Science, Pharmacy and Chemistry, Kingston University London, Penrhyn Road, Kingston-upon-Thames, Surrey KT1 2EE, UK

E-mail: h.modjtahedi@kingston.ac.uk

Abbreviations: EGFR, epidermal growth factor receptor; CDK, cyclin-dependent kinase; HPCCLs, human pancreatic cancer cell lines; TKIs, tyrosine kinase inhibitors; CDKI, cyclin-dependent kinase inhibitor

Key words: pancreatic cancer, targeted therapy, HER family, cyclin-dependent kinases, SRC, STAT3, tyrosine kinase inhibitors, combinational therapy with $\mathrm{IC}_{50}$ values of $\leq 10 \mathrm{nM}$, followed by SRC targeting TKI dasatinib $\left(\mathrm{IC}_{50}\right.$ of $\left.\leq 258 \mathrm{nM}\right)$, gemcitabine $\left(\mathrm{IC}_{50}\right.$ of $\left.\leq 330 \mathrm{nM}\right)$, stattic $\left(\mathrm{IC}_{50}\right.$ of $\left.\leq 2 \mu \mathrm{M}\right)$ and the irreversible pan-HER TKI afatinib $\left(\mathrm{IC}_{50}\right.$ of $\left.\leq 2.95 \mu \mathrm{M}\right)$. Treatment with afatinib and dasatinib inhibited the ligand-induced phosphorylation of EGFR and SRC respectively. Statistically significant associations were found between HER 2 expression and response to treatment with the ALK/IGF-IR/InsR inhibitor ceritinib and fibroblast growth factor receptor (FGFR)1/2/3 inhibitor AZD4547, HER3 and IGF-IR expression and their response to treatment with TKIs targeting HER family members (erlotinib and afatinib), and c-MET and ALK7 expression and their response to treatment with stattic. Interestingly, treatment with a combination of afatinib with dasatinib and gemcitabine with dasatinib resulted in synergistic tumor growth inhibition in all HPCCLs examined. In contrast, the combination of afatinib with dinaciclib was found to be antagonistic. Finally, the treatment with afatinib, dasatinib and dinaciclib strongly inhibited the migration of all HPCCLs examined. In conclusion, the CDK1/2/5/9 inhibitor dinaciclib, irreversible pan-HER TKI afatinib and SRC targeting TKI dasatinib were most effective at inhibiting the proliferation and migration of HPCCLs and the combination of afatinib with dasatinib and gemcitabine with dasatinib led to synergistic tumor growth inhibition in all HPCCLs examined. Our results support further investigation on the therapeutic potential of these combinations in future clinical trials in pancreatic cancer.

\section{Introduction}

Pancreatic cancer is one of the deadliest types of human cancer. Globally, there were an estimated 458,918 new cases of pancreatic cancer and 432,242 pancreatic cancer deaths in $2018(1,2)$. In the USA, there will be an estimated 57,600 new cases of pancreatic cancer and 47,050 pancreatic cancer-related 
deaths in 2020 (3). Several modifiable risk factors i.e., smoking, alcohol, obesity, Helicobacter pylori infection and non-modifiable factors such as age, sex (male predominance), race/ethnicity (higher incidence in black population), blood group (A, B and AB), family history and genetic susceptibility (e.g., BRCA2 mutation) have been identified that increase the likelihood of developing pancreatic cancer (2-6). Despite preventive measures (e.g., avoidance of above risk factors) and numerous advances in the imaging technologies and the development of cancer therapeutics in the past few decades, around $80-85 \%$ of patients with pancreatic cancer have an unresectable tumor at the time of presentation with the 5-year survival rate of only $9 \%$ (2-6). Therefore, there is an urgent need not only to identify biomarkers of diagnostic, prognostic and predictive value but also to develop more effective and less toxic therapeutic interventions.

Growth factor receptor tyrosine kinases (RTKs) with tyrosine kinase activity and their downstream cell signaling molecules are important not only in normal development but also when aberrantly expressed or activated in the pathogenesis of human cancers and therapeutic targets. One such example is the human epidermal growth factor receptor subfamily (also called EGFR or ErbB family) which consists of four members; ErbB1/HER1/(also called EGFR), ErbB2/HER2, ErbB3/HER3 and ErbB4/HER4 (7). Upon ligand binding (EGF, AR and TGF $\alpha$ for EGFR, HB-EGF, BTC, Epiregulin for EGFR/HER4 and NGR1-4 for HER3/4) conformational changes in the extracellular domain of ErbB receptor are induced resulting in the formation of homodimers or heterodimers between ErbB family members. This leads to an auto and/or trans-phosphorylation of C-terminal region of the intracellular tyrosine kinase domain leading to the activation of various downstream signaling pathways such as PI3K-AKT, RAS/RAF/MAPK, JAK-STAT and $P L C-\gamma 1$ that regulates proliferation, metabolism, angiogenesis, cell progression and survival (7-9). In some studies, aberrant expression and activation of HER-mediated signaling has been associated with tumor aggressiveness and a poorer prognosis in patients with pancreatic cancer (7,10-13). However, of the HER inhibitors, only the reversible EGFR-specific erlotinib has been approved by the US FDA for the treatment of locally advanced, unresectable or metastatic pancreatic cancer when used in combination with gemcitabine (14). While erlotinib treatment improved patient survival, the duration of response is usually short with both primary and secondary resistance being the major causes of the treatment failure (14). Therefore, it is imperative to discover more effective and less toxic therapeutic agents for the treatment of patients with pancreatic cancer (7).

In addition to the HER family members, deregulation of other subfamilies of RTKs including insulin-like growth factor 1 receptor (IGF-IR), c-MET and anaplastic lymphoma kinase (ALK) as well as non-RTKs including SRC have been reported in pancreatic cancer (7,15-19), For example, overexpression and activation of IGF-IR has been associated with the aggressiveness, poor prognosis and resistance to anti-HER targeted therapy in some patients with pancreatic cancer (15). Increased SRC activity has also been reported in more than $60 \%$ of pancreatic cancers resulting in increased crosstalk between tumor cells and the surrounding stroma ultimately leading to increased tumorigenesis, metastasis and a poorer response to therapy (20-22). Preclinical studies have shown the effectiveness of dasatinib in treating patients with pancreatic cancer; however, it has failed to demonstrate significant results in clinical trials (23) suggesting that dasatinib monotherapy may not be of therapeutic value in patients with pancreatic cancer. Therefore, further studies of such agents in combination with other agents are warranted.

In recent years, both the heterogeneous nature of pancreatic cancer and its complex biology and tumor microenvironment have been associated with resistance to therapy (24-26). In our previous study, we demonstrated that the second generation pan-HER family blocker, afatinib, was more effective than the first generation EGFR TKIs erlotinib and gefitinib in inhibiting the growth of human pancreatic cancer cells (27). We also reported the superiority of afatinib when used in combination with the IGF-IR inhibitor NVP-AEW541 (15). The aim of this study was to investigate the sensitivity of a panel of human pancreatic cancer cell lines established from patients at different stages of the disease to treatment with agents targeting various growth factor receptors such as HER family members (afatinib and erlotinib), c-MET (crizotinib and capmatinib), ALK (ceritinib and brigatinib), IGF-IR (NVP-AEW742 and linsitinib), SRC family (dasatinib, bosutinib and ponatinib), CDK inhibitors (palbociclib and dinaciclib), STAT3 inhibitor (stattic) and cytotoxic agent (gemcitabine) both as single agents and/or in combination. We also investigated the association between the cell surface expression of various growth factor receptors and their response to treatment with the above agents. Furthermore, the effect of selected agents on the phosphorylation of HER receptors and subsequent downstream signaling molecules, cell cycle distribution and migration of human pancreatic cancer cell lines were determined.

\section{Materials and methods}

Tumor cell lines. A panel of seven human pancreatic cancer cell lines (HPCCLs) was used in this study including BxPC-3, Capan-1, FA-6, Panc-1, Mia-Paca-2, Hs766T and CF-PAC-1. All cell lines were cultured routinely at $37^{\circ} \mathrm{C}$ in a humidified atmosphere $\left(5 \% \mathrm{CO}_{2}\right)$ as described previously $(15,28)$. BxPC-3, Capan-1 and FA-6 were cultured in RPMI-1640 medium (Sigma-Aldrich; Merck KGaA), Panc-1, Mia-Paca-2 and Hs766T were cultured in Dulbecco's modified Eagle's medium (DMEM) (Merck) and CF-PAC-1 was cultured in Iscove's modified medium each supplemented with $10 \%$ fetal bovine serum (FBS) (heat inactivated) (Sigma-Aldrich; Merck KGaA), antibiotics penicillin $(50 \mu \mathrm{g} / \mathrm{ml})$, streptomycin $(50 \mu \mathrm{g} / \mathrm{ml})$ and neomycin $(50 \mu \mathrm{g} / \mathrm{ml})$ (Sigma-Aldrich; Merck KGaA). RPMI-1640 and Iscove's modified Dulbecco's medium were supplemented with 2 and $8 \mathrm{mM}$ L-glutamine (Sigma-Aldrich; Merck KGaA) respectively.

Tyrosine kinase inhibitors and antibodies. Gemcitabine and crizotinib were purchased from Healthcare at Home (Burton on Trent, UK) and Tocris (Avonmouth, UK), respectively. Afatinib, NVP-AEW742, stattic, brigatinib, linsitinib, ceritinib, crenolanib, ponatinib, dasatinib, bosutinib, AZD4547, palbociclib, erlotinib and dinaciclib were all purchased from Selleckchem (Europe Ltd. UK). The antibodies for 
flow cytometry including mouse anti-EGFR (HM43.16B) and anti-HER2 (HM50.67A) were raised in-house against the external domain of these receptors (29) whereas mouse anti-HER3 (MAB3481), anti-HER4 (MAB11311), ALK7 (MAB77491), HGF R/c-MET (MAB3582), PDGFR $\alpha$ (MAB1264), PDGFR $\beta$ (MAB1263) and IGF-IR (MAB391) were purchased from R\&D Systems (Europe Ltd. UK) and Insight Biotechnology (Middlesex, UK), respectively. The anti-mouse IgG FITC-conjugated STAR9B was purchased from Serotec Ltd. (Oxford, UK). The antibodies for western blot analysis including mouse anti-EGFR monoclonal antibody (mAb) (clone F4) and phosphor-Tyr-100 were obtained from Merck (Dorset UK) and Cell Signaling Technology, Inc. (Hitchin, UK) respectively. The rabbit anti-phospho-EGFR (Tyr 1068), MAPK, phospho-MAPK (Tyr204), Akt, phospho-AKt (Ser473), STAT3, phospho-STAT3 (Tyr705), SRC, phospho-SRC (Tyr416), phospho-IGF-IR and $\beta$-actin were all obtained from Cell Signaling Technology, Inc. Both the goat anti-mouse IgG IRDye $800 \mathrm{CW}$ and donkey anti-rabbit IgG IRDye 680RD was purchased from LI-COR Ltd. (Cambridge, UK).

Flow cytometry. The surface expression of various growth factor receptors on HPCCLs was accessed by flow cytometry as described previously $(27,30)$. Approximately $1 \times 10^{6}$ cells suspended in $2 \%$ FBS medium were added to $1.5 \mathrm{ml}$ Eppendorf, centrifuged ( $254 \mathrm{x}$ g for $3 \mathrm{~min}$ ), washed once with cold PBS and incubated with or without $10 \mu \mathrm{g} / \mathrm{ml}$ of the primary antibody by rotation at $4^{\circ} \mathrm{C}$ for $1 \mathrm{~h}$. Following that, the cells were washed thrice with $1 \mathrm{ml}$ of cold PBS by centrifugation (254 $\mathrm{x} \mathrm{g}$ for $3 \mathrm{~min}$ ) and incubated with secondary antibody STAR9B (1:200 dilution) by rotation at $4^{\circ} \mathrm{C}$ for $1 \mathrm{~h}$. Finally, the cells were washed thrice with cold PBS by centrifugation and re-suspended in $1 \mathrm{ml}$ of FACS flow buffer (Becton Dickinson UK, Ltd., Oxford). FACS analysis was carried out using Cell Quest Pro software (Becton Dickinson, version 6.0). A minimum of 10,000 events were measured through excitation of argon laser at $488 \mathrm{~nm}$ using an FITC detector $(525 \mathrm{~nm})$ as part of the BD FACS Calibur Flow cytometer (BD Biosciences).

Growth inhibition studies. In order to determine the effect of various agents on the proliferation of HPCCLs, sulforhodamine B (SRB; Sigma-Aldrich; Merck KGaA) colorimetric assay was used as described previously (27). Briefly, $5 \times 10^{3}$ cells/well were seeded in $100 \mu \mathrm{l}$ of growth medium supplemented with $2 \% \mathrm{FBS}$ in a 96 -well plate and incubated at $37^{\circ} \mathrm{C}$ (in a humidified atmosphere in $5 \% \mathrm{CO}_{2}$ ). Following a 4-h incubation, 'time zero' plate (representing the number of cells prior to treatment) was fixed with $10 \%$ trichloroacetic acid (Fisher Scientific, Loughborough, UK) for $1 \mathrm{~h}$ at room temperature, washed thrice with tap water and left to air dry overnight. For other plates, $100 \mu \mathrm{l}$ of doubling dilutions of agents were added to each well in triplicate and incubated at $37^{\circ} \mathrm{C}$ until the controls (medium only) became confluent. These plates were then fixed as mentioned above, stained with $0.04 \%$ (w/v) SRB in $1 \%$ acetic acid for $1 \mathrm{~h}$, washed thoroughly with $1 \%$ acetic acid and left to air dry overnight. The stained cells were solubilized with $100 \mu \mathrm{l} /$ well of $10 \mathrm{mM}$ Tris-Base and the absorbance of each well was measured at $565 \mathrm{~nm}$ using an Epoch plate reader
(Thermo Fisher Scientific, Inc.). Growth as a percentage of control was determined using the following formula:

$$
\% \text { Cell Growth }=\frac{X-Y}{Z-Y} \times 100 ;
$$

where $X$ is the absorbance of the drug-treated well at $565 \mathrm{~nm}$, $\mathrm{Y}$ is the absorbance prior to treatment at $565 \mathrm{~nm}$ and $\mathrm{Z}$ is the absorbance of the untreated cells at $565 \mathrm{~nm}$.

The $50 \%$ inhibitory concentration of each agent $\left(\mathrm{IC}_{50}\right)$ was calculated using the non-linear least squares curve fitting (four parameter analysis, log (inhibitor) vs response, variable slope) using Gen5 software (BioTeck, UK).

Cell cycle distribution analysis. The effect of selected agents including inhibitors of HER family members, CDK, SRC, STAT3 and cytotoxic agent on the cell cycle distribution of HPCCLs was investigated using flow cytometry. Approximately, $0.5 \times 10^{6}$ cells/well were seeded in $5 \mathrm{ml}$ of $2 \%$ FBS medium with or without drugs at $\mathrm{IC}_{70}$ and incubated at $37^{\circ} \mathrm{C}$ until the control wells (no drugs) became almost confluent. Following that, the cells were harvested by trypsinization and pooled with their respective supernatants, washed once with cold PBS by centrifugation ( $264 \mathrm{x} \mathrm{g}$ for $4 \mathrm{~min}$ ) and fixed with $70 \%$ ice-cold ethanol for minimum of $3 \mathrm{~h}$ at $-20^{\circ} \mathrm{C}$. The cells were collected by centrifugation ( $450 \mathrm{x} \mathrm{g}$ for $5 \mathrm{~min}$ ) washed thrice with cold PBS and stained with Guava cell cycle reagent (Luminex). Cells were then run through a Guava EasyCyte $^{\mathrm{TM}}$ flow cytometer (Luminex Corp.) where 5,000 events were recorded by excitation with a $\operatorname{argon}$ laser $(488 \mathrm{~nm})$ using Yellow-B fluorescence $(583 / 26 \mathrm{~nm})$ and analyzed using Incyte $^{\mathrm{TM}}$ soft 3.3 (Luminex Corp.).

Determination of the combination index. The effect of selected agents on the growth of HPCCLs when used in combination was assessed using SRB assay as described previously (27). For each combination, two agents (TKIs or cytotoxic agent) were mixed at their respective $4 \mathrm{x} \mathrm{IC}_{50}$ value (determined previously as a single agent) followed by eight doubling dilutions. Data analysis was performed using Calcusyn software (Biosoft, UK) and interpreted as follow: $<0.9=$ synergistic effect, 0.9-1.1=additive effect, $>1.1=$ antagonistic effect.

Western blot analysis. The effect of various agents on downstream signaling molecules of BxPC-3 and Capan-1 cells was investigated using western blot analysis. Briefly, $0.5 \times 10^{6}$ cells/well were grown in $5 \mathrm{ml}$ of $10 \%$ FBS RPMI-1640 medium in 6-well plate to near confluency. Cells were washed once with $5 \mathrm{ml}$ of $0.5 \%$ FBS RPMI-1640 medium and incubated at $37^{\circ} \mathrm{C}$ with the desired drug at a final concentration of $400 \mathrm{nM}$ (or no inhibitor/medium only as a negative control) in $5 \mathrm{ml}$ of fresh $0.5 \%$ FBS RPMI-1640 medium for $1 \mathrm{~h}$. After that, the cancer cells were incubated for a further $15 \mathrm{~min}$ with EGF, HB-EGF or IGF-II or no ligand. The cells were then washed once with PBS and lysed with $400 \mu$ l of preheated lysis buffer (Invitrogen; Thermo Fisher Scientific, Inc.) containing protease inhibitor cocktail (Sigma-Aldrich; Merck KGaA) and homogenized using $25 \times 5 / 8$ ' gauge needles in order to reduce its viscosity. Protein samples $(30 \mu \mathrm{g})$ were separated on $4-12 \%$ Bis-Tris gel (Invitrogen; Thermo Fisher Scientific, Inc.) using the XCell II Surelock Mini-Cell system (Invitrogen; Thermo 
Fisher Scientific, Inc.) and transferred onto Immobilon-FL PVDF membranes (Merck) using XCell II Mini-Cell Blot Module kit (Invitrogen; Thermo Fisher Scientific, Inc.). The PVDF membranes were probed with various antibodies at the manufacturer's recommended dilutions and visualized using the LI-COR Image Studio software (version 1.x-2.x).

Scratch wound healing assay. The effect of selected agents on the migration of HPCCLs was investigated using scratch wound healing experiment. Briefly, $1 \times 10^{5}$ cells/100 $\mu \mathrm{l}$ of $10 \%$ FBS medium per well were seeded in a corning CELLBIND ${ }^{\mathrm{TM}}$ 96-well clear flat bottom sterile plate (Sigma-Aldrich; Merck $\mathrm{KGaA}$ ). Following $24 \mathrm{~h}$ of incubation at $37^{\circ} \mathrm{C}$, wounds were created using a wound maker, carefully aspirating medium from each well. After washing with PBS, cells were treated with $200 \mu \mathrm{l}$ of $10 \%$ FBS medium containing various drugs or medium only as positive control. The plate was then placed onto the IncuCyte Zoom ${ }^{\circledR}$ instrument at $37^{\circ} \mathrm{C}$ for $72 \mathrm{~h}$ where cells were analyzed every $3 \mathrm{~h}$ using Incucyte Zoom ${ }^{\circledR}$ software (Essen Bioscience, version 2018A).

Statistical analysis. The statistical analysis was carried out using SPSS software (IBM ${ }^{\circledR}$, SPSS statistics version 26). Linear regression analysis was used to assess the relationship between the expression of HER family members and response to treatment with various TKIs, CDK inhibitor, STAT3 inhibitor and cytotoxic agent. The effect of selected agents on the migration of pancreatic cancer cell lines were tested by paired t-test analysis. A P-value of $\leq 0.05$ was considered to be statistically significant and an $\mathrm{R}^{2}$ value closer to 1 showed the reliability of the association between the $\mathrm{IC}_{50}$ value of each drug and expression level of each marker. All statistical analyses were carried out using SPSS statistics 26 (SPSS Inc.).

\section{Results}

Cell surface expression of various growth factor receptors in pancreatic cancer cell lines. We determined the expression level of various membrane bound growth factor receptors including HER family members, IGF-IR, c-MET and ALK7 in seven HPCCLs using flow cytometry and the results are represented as mean fluorescence intensity (MFI) and histograms (Table I, Fig. 1). Most cell lines were found to have high expression for EGFR and moderate expression for HER2. In comparison to control EGFR-overexpressing breast cell line MDA-MB-468 (MFI=806), the MFI values for EGFR expression in our panel ranged from moderate (Mia-Paca-2, MFI=21.1) to high (Hs766T, MFI=236.9). Similarly, in comparison to control HER2-overexpressing ovarian cancer cell line SKOV3 (MFI=385), the MFI values for HER2 expression in our panel of HPCCLs ranged from low (Hs766T, MFI=11.2) to moderate (Capan-1, MFI=33.1). The expression level of HER3 and HER4 was undetectable to very low in most of the cell lines. Finally, in comparsion to the IGF-IR and ALK7-positive breast cancer cell lines MDA-MB231 (MFI of 23 and 20, respectively) and c-MET positive MDA-MB468 (MFI=35), our panel of human pancreatic cancer cells had low to moderate level of expression with BxPC-3 cells having the highest expression of both IGFIR (MFI=28.4) and ALK (MFI=50.2) and Hs766T having the highest level of expression of C-MET with an MFI value of 50.8 respectively (Table I).

Growth response of human pancreatic cancer cell lines to treatment with various TKIs, CDK inhibitors, STAT3 inhibitor and cytotoxic agent. The effect of various agents on the growth of HPCCLs was determined using SRB assay and the results are expressed as $\mathrm{IC}_{50}$ (Table II, Fig. 2). Of all the agents tested, the CDK1/2/5/9 inhibitor dinaciclib was the most potent agent inhibiting the growth of all seven cell lines with the $\mathrm{IC}_{50}$ values of $\leq 10 \mathrm{nM}$. This was followed by the Abl/Src/c-kit TKI dasatinib with $\mathrm{IC}_{50}$ values of $13 \mathrm{nM}$ (CF-PAC1) to $258 \mathrm{nM}$ (Panc-1); gemcitabine with $\mathrm{IC}_{50}$ of $\leq 330 \mathrm{nM}$; the STAT3 inhibitor, static, with $\mathrm{IC}_{50}$ values of $0.74 \mu \mathrm{M}$ (Panc-1) to $2 \mu \mathrm{M}$ (BxPC-3) and the irreversible pan-HER TKI afatinib with $\mathrm{IC}_{50}$ of $27 \mathrm{nM}$ (BxPC-3) to $2.95 \mu \mathrm{M}$ (FA-6). The morphology of BxPC-3 cells following treatment with the above agents compared to the control are presented in Fig. 3. The effect of c-MET/ALK inhibitor, crizotinib, ALK/IGF-IR/InsR inhibitor ceritinib, Abl/PDGFR $\alpha /$ VEGFR2/FGFR1/Src inhibitor ponatinib and Src/Abl inhibitor, bosutinib, on the growth of all HPCCLs was found to be moderate (Table II). However, treatment with the PDGFR $\alpha / \beta$ inhibitor crenolanib, FGFR $1 / 2 / 3$ inhibitor AZD4547, c-MET inhibitor capmatinib, IGF-IR inhibitor NVP-AEW742, and IGF-IR/InsR inhibitor brigatinib had minimum to no inhibitory effect on HPCCLs (Table II).

Cell cycle distribution analysis. The effect of various agents on the cell cycle distribution of four HPCCLs was determined using flow cytometry and the results are summarized in Table III. Treatment with afatinib, dinaciclib, dasatinib, stattic and gemcitabine increased the percentage of cells in the sub-G1 phase (apoptotic/dead cells) with subsequent reduction in the G0/G1 phase. Furthermore, treatment with afatinib and dasatinib increased cells in the $\mathrm{S}$ and G2/M phase whereas treatment with dinaciclib and gemcitabine increased cells in the $\mathrm{S}$-phase in most of the cell lines examined. The representative flow cytometry plots of cell cycle distribution of BxPC-3 cells following treatment with these agents is shown in Fig. S1.

\section{Afatinib and dasatinib blocks the phosphorylation of EGFR} and $S R C$ respectively. Next we investigated the effects of treatment with afatinib, dinaciclib, dasatinib and stattic on the phosphorylation of growth factor receptors and downstream cell signaling molecules in BxPC-3 and Capan-1 cells. As expected, afatinib blocked the ligand-induced phosphorylation of tyrosine and phosphorylation of EGFR at position 1,068 which in turn resulted in reduction in the phosphorylation of downstream signaling molecules such as MAPK and AKT in both cell lines examined (BxPC-3 and Capan-1) (Fig. 4A and B). Treatment with dasatinib alone was accompanied by the EGF, HB-EGF and IGF-II induced phosphorylation of SRC. However, no phosphorylation of the IGF-IR was evident following treatment with EGF, HB-EGF and IGF-II in these two cancer cell lines (data not shown).

Synergistic and antagonistic effect of various drug combinations in pancreatic cancer cell lines. The combined effect of various agents including afatinib, dinaciclib, dasatinib, stattic 
Table I. Surface expression of various growth factor receptors in human pancreatic cancer cell lines.

Mean fluorescence intensity

\begin{tabular}{lcccccccc}
\cline { 2 - 8 } Pancreatic cancer cell lines & Control & EGFR & HER2 & HER3 & HER4 & IGF-IR & C-MET & ALK7 \\
\hline BxPC-3 (primary tumor) & $4.1 \pm 0.3$ & $195.6 \pm 36.1$ & $22.5 \pm 4.5$ & $12.7 \pm 1.3$ & $11.1 \pm 0.2$ & $28.4 \pm 2.2$ & $40.5 \pm 5.3$ & $50.2 \pm 9.7$ \\
Capan-1 (liver metastasis) & $5.3 \pm 0.4$ & $63.6 \pm 6.8$ & $33.12 \pm 3.2$ & $8.4 \pm 0.5$ & $7.5 \pm 0.4$ & $22.3 \pm 0.2$ & $23.5 \pm 0.9$ & $24.3 \pm 0.6$ \\
FA-6 (unknown) & $4.1 \pm 0.5$ & $133.6 \pm 11.5$ & $13.9 \pm 0.3$ & $8.67 \pm 0.1$ & $6.48 \pm 0.5$ & $9.1 \pm 0.4$ & $17.2 \pm 0.5$ & $24.0 \pm 0.3$ \\
Panc-1 (primary tumor) & $5.0 \pm 0.5$ & $232.6 \pm 4.4$ & $32.3 \pm 4.6$ & $7.37 \pm 0.4$ & $11.41 \pm 0.1$ & $20.3 \pm 1.5$ & $5.0 \pm 0.0$ & $23.5 \pm 1.3$ \\
Mia-Paca2 (primary tumor) & $4.9 \pm 0.1$ & $26.0 \pm 9.1$ & $22.6 \pm 0.5$ & $5.26 \pm 0.2$ & $7.93 \pm 0.3$ & $16.8 \pm 0.5$ & $6.0 \pm 0.2$ & $6.8 \pm 0.0 .4$ \\
Hs766T (lymph node metastasis) & $4.1 \pm 0.6$ & $241 \pm 4.5$ & $11.2 \pm 0.4$ & $10.4 \pm 0.1$ & $15.5 \pm 0.4$ & $16.1 \pm 0.8$ & $50.8 \pm 7.2$ & $37.5 \pm 3.0$ \\
CF-PAC1 (liver metastasis) & $4.5 \pm 0.5$ & $96.7 \pm 7.8$ & $48.3 \pm 1.4$ & $18.1 \pm 0.8$ & $9.52 \pm 0.2$ & $26.2 \pm 3.2$ & $38.8 \pm 4.2$ & $26.3 \pm 0.6$ \\
\hline
\end{tabular}

Controls

\begin{tabular}{lcccccccc}
\hline MDA-MB-468 & $4.4 \pm 0.3$ & $806.1 \pm 0.5$ & N/A & N/A & N/A & N/A & $35.3 \pm 1.7$ & N/A \\
SKOV3 (ovarian) & $4.1 \pm 0.2$ & N/A & $385.2 \pm 0.4$ & N/A & N/A & N/A & N/A & N/A \\
MDA-MB-231 & $4.0 \pm 0.3$ & N/A & N/A & N/A & N/A & $23.2 \pm 0.6$ & N/A & $20.3 \pm 1.9$ \\
\hline
\end{tabular}

N/A, not available. MDA-MB-231, MBA-MB-468 and SKOV3 cell lines were used as positive controls. EGFR, epidermal growth factor receptor; HER, human epidermal growth factor receptor; IGF-IR, insulin-like growth factor 1 receptor.
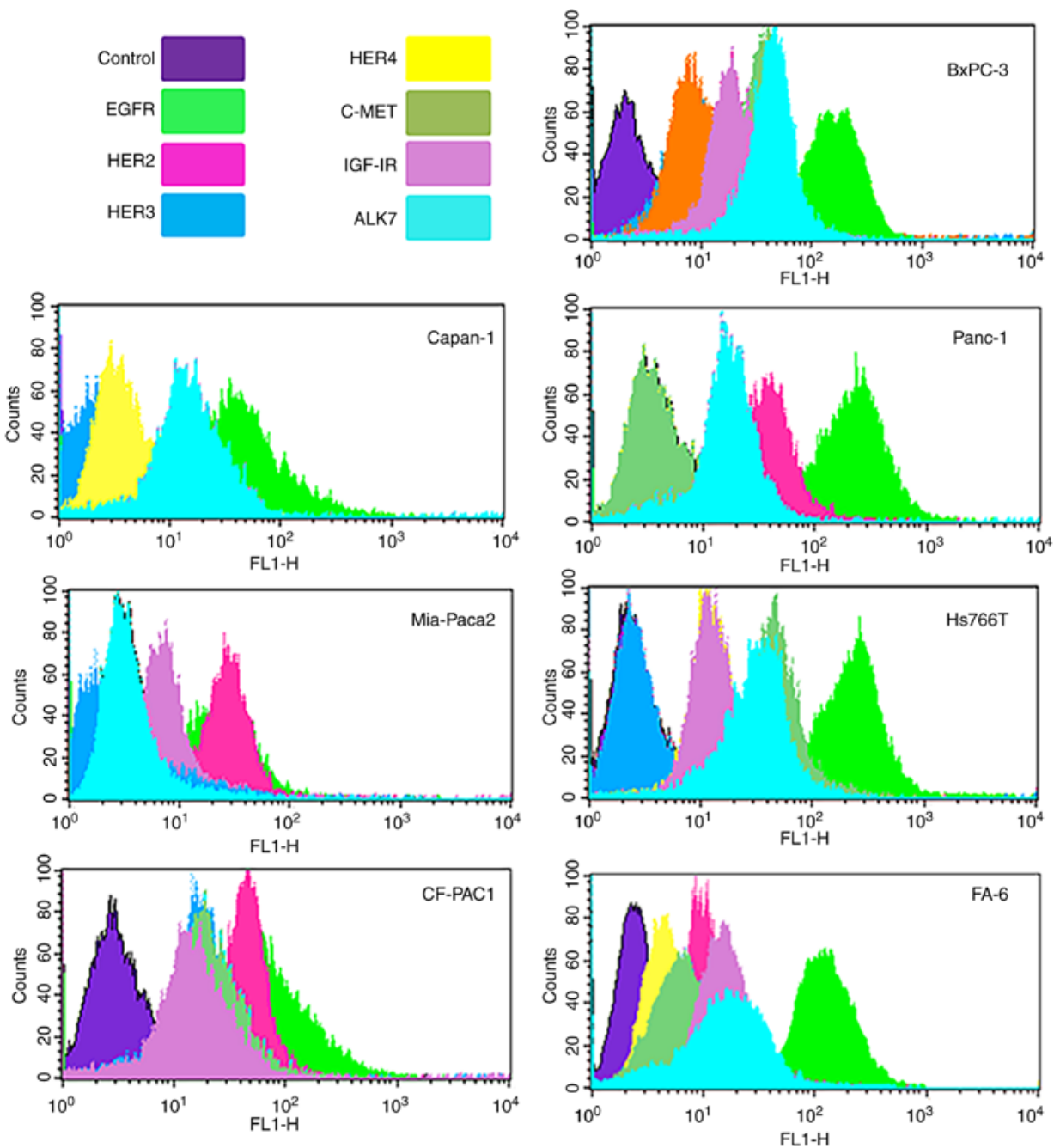

Figure 1. The membrane bound expression level of various growth factor receptors determined by flow cytometry in human pancreatic cancer cell lines represented as histograms. EGFR, epidermal growth factor receptor; HER, human epidermal growth factor receptor; c-MET, mesenchymal-epithelial transition factor; IGF-IR, insulin-like growth factor 1 receptor; ALK7, anaplastic lymphoma kinase 7. 


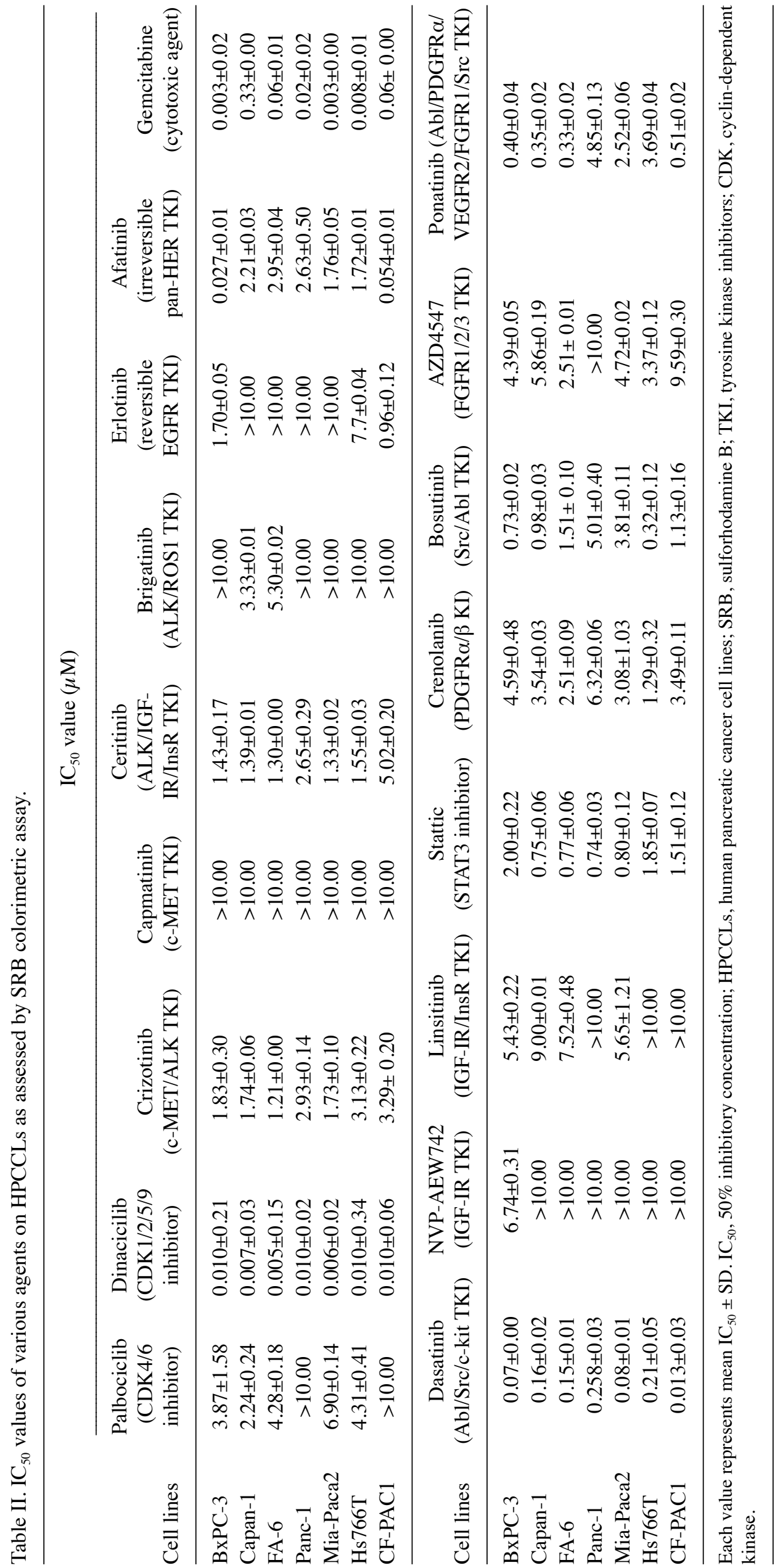




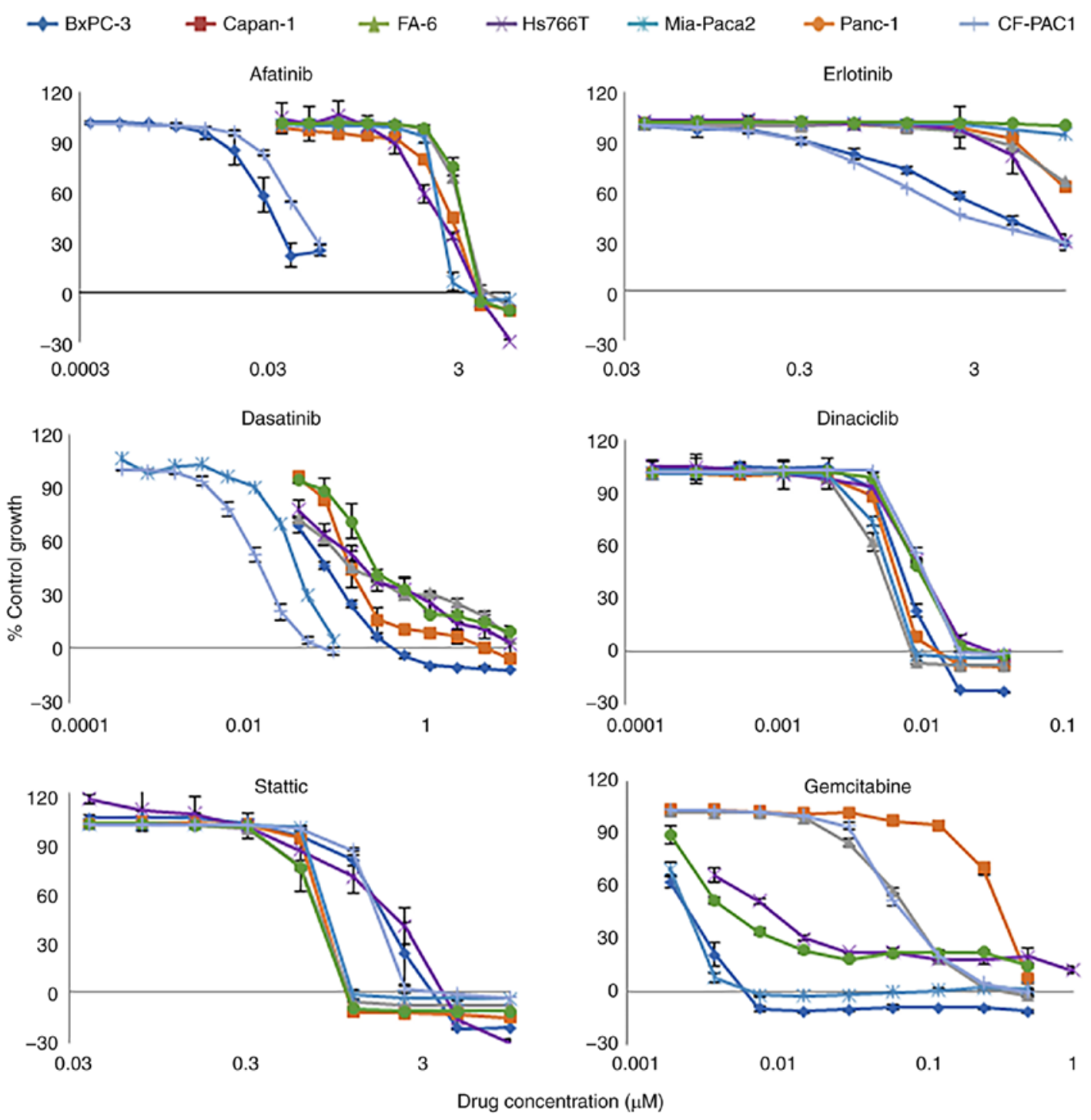

Figure 2. Effect of doubling dilutions of TKIs targeting HER family members and SRC family kinases, inhibitors of CDK and STAT3 and cytotoxic agent on the growth of human pancreatic cell lines. Cells were grown in $2 \%$ FBS growth medium with or without drugs until control cells (only medium) were confluent. Each point represents the mean \pm SD of the triplicate sample. TKIs, tyrosine kinase inhibitors; HER, human epidermal growth factor receptor; CDK, cyclin-dependent kinase; STAT3, signal transducer and activator of transcription 3.

and gemcitabine on the growth of HPCCLs was investigated. Only treatment with a combination of dasatinib with afatinib or dasatinib in combination with gemcitabine led to synergistic growth inhibition of four HPCCLs (Table IV). In contrast, treatment with a combination of afatinib with dinaciclib was found to be antagonistic in all of four HPCCLs examined (Table IV). Finally, treatment with other drug combinations resulted in mixed effects in all cell lines examined (data not shown).

Linear regression analysis. The association between the expression level of various growth factor receptors and their response to treatment with various agents was assessed using SPSS software (Table V). There was no correlation between expression level of EGFR and the response to treatment with various agents. However, there were some statistically significant associations between HER 2 expression and the response to treatment with ALK/IGF-IR/InsR inhibitor ceritinib $\left(\mathrm{R}^{2}=0.698, \mathrm{P}=0.019\right)$ and the FGFR1/2/3 inhibitor AZD4547
$\left(\mathrm{R}^{2}=0.751, \mathrm{P}=0.012\right)$; HER3 expression and the response to treatment with HER family targeting TKI erlotinib $\left(\mathrm{R}^{2}=0.830\right.$, $\mathrm{P}=0.004)$ and afatinib $\left(\mathrm{R}^{2}=0.599, \mathrm{P}=0.041\right)$; IGF-IR expression and the response to treatment with erlotinib $\left(R^{2}=0.608\right.$, $\mathrm{P}=0.039)$ and afatinib $\left(\mathrm{R}^{2}=0.672, \mathrm{P}=0.024\right)$. In addition, a statistically significant association was found between c-MET expression and the response to treatment with STAT3 inhibitor stattic $\left(\mathrm{R}^{2}=0.809, \mathrm{P}=0.006\right)$ and $\mathrm{SRC} / \mathrm{Abl}$ inhibitor bosutinib $\left(\mathrm{R}^{2}=0.747, \mathrm{P}=0.012\right)$ and finally between ALK7 expression and the response to treatment with STAT3 inhibitor stattic $\left(\mathrm{R}^{2}=0.682, \mathrm{P}=0.022\right)$. HER4 was not tested due to its negative expression in all cell lines.

Effect of selected agents on the migration of pancreatic cancer cell lines. The effect of selected agents on the migration of four HPCCLs was determined using scratch wound healing assay and the results at time points 6,12 and $24 \mathrm{~h}$ are summarized in Fig. 5A. As an example, the effect of these agents on the migration of BxPC-3 cells at $24 \mathrm{~h}$ is shown in Fig. $5 \mathrm{~B}$. In comparison to 
Table III. Effect of various agents on the cell cycle distribution of human pancreatic cancer cell lines.

\begin{tabular}{lcccc}
\hline Cell line/treatment & Sub G1 & $\mathrm{G} 0 / \mathrm{G} 1$ & $\mathrm{~S}$ & $\mathrm{G} 2 / \mathrm{M}$ \\
\hline BxPC3/ & & & & \\
Control & $5.28 \pm 0.36$ & $65.65 \pm 3.54$ & $16.70 \pm 1.65$ & $11.63 \pm 2.60$ \\
Afatinib & $8.88 \pm 1.84$ & $52.25 \pm 4.60$ & $18.60 \pm 2.40$ & $19.36 \pm 5.45$ \\
Dinaciclib & $24.30 \pm 9.93$ & $41.36 \pm 13.85$ & $22.75 \pm 3.26$ & $10.76 \pm 3.23$ \\
Dasatinib & $21.51 \pm 8.26$ & $38.57 \pm 15.23$ & $19.52 \pm 0.37$ & $16.57 \pm 4.55$ \\
Stattic & $39.05 \pm 11.89$ & $38.89 \pm 8.63$ & $15.00 \pm 0.16$ & $6.86 \pm 0.56$ \\
Gemcitabine & $20.20 \pm 7.98$ & $46.04 \pm 20.80$ & $22.55 \pm 12.52$ & $10.37 \pm 2.31$ \\
Capan-1/ & & & & \\
Control & $18.37 \pm 5.98$ & $60.75 \pm 0.41$ & $13.63 \pm 3.98$ & $7.53 \pm 3.20$ \\
Afatinib & $44.77 \pm 15.22$ & $44.92 \pm 11.96$ & $8.26 \pm 3.37$ & $2.32 \pm 1.42$ \\
Dinaciclib & $58.17 \pm 15.68$ & $35.03 \pm 15.63$ & $6.79 \pm 2.50$ & $1.00 \pm 0.30$ \\
Dasatinib & $42.79 \pm 19.48$ & $39.45 \pm 13.99$ & $14.20 \pm 5.96$ & $4.00 \pm 1.92$ \\
Stattic & $67.61 \pm 37.94$ & $25.45 \pm 29.59$ & $6.70 \pm 8.70$ & $2.03 \pm 2.66$ \\
Gemcitabine & $62.72 \pm 18.94$ & $32.91 \pm 17.64$ & $4.35 \pm 3.16$ & $0.59 \pm 0.50$ \\
FA-6/ & & & & \\
Control & $3.73 \pm 2.26$ & $57.63 \pm 1.85$ & $24.00 \pm 0.81$ & $13.88 \pm 4.01$ \\
Afatinib & $16.60 \pm 9.44$ & $30.99 \pm 4.25$ & $31.47 \pm 0.33$ & $18.79 \pm 3.44$ \\
Dinaciclib & $17.45 \pm 9.18$ & $29.61 \pm 5.42$ & $33.25 \pm 3.01$ & $18.48 \pm 4.99$ \\
Dasatinib & $5.70 \pm 5.87$ & $28.86 \pm 9.48$ & $43.17 \pm 10.81$ & $19.19 \pm 4.88$ \\
Stattic & $31.94 \pm 2.81$ & $20.61 \pm 1.88$ & $31.49 \pm 2.26$ & $14.02 \pm 0.30$ \\
Gemcitabine & $11.86 \pm 6.78$ & $42.07 \pm 18.45$ & $35.83 \pm 8.05$ & $9.47 \pm 3.11$ \\
Mia-Paca2/ & & & & $12.63 \pm 3.25$ \\
Control & $1.82 \pm 1.85$ & $68.67 \pm 2.14$ & $16.46 \pm 1.59$ & $20.95 \pm 17.16$ \\
Afatinib & $17.70 \pm 23.89$ & $22.57 \pm 16.79$ & $39.67 \pm 7.94$ & $11.69 \pm 8.92$ \\
Dinaciclib & $17.58 \pm 20.83$ & $40.94 \pm 15.47$ & $29.90 \pm 0.51$ & $18.68 \pm 0.49$ \\
Dasatinib & $2.10 \pm 0.36$ & $52.91 \pm 9.14$ & $24.93 \pm 5.55$ & $14.50 \pm 10.83$ \\
Stattic & $24.19 \pm 33.06$ & $32.28 \pm 25.82$ & $22.16 \pm 10.65$ & \\
Gemcitabine & $3.14 \pm 1.23$ & $38.97 \pm 12.76$ & $43.88 \pm 25.77$ & \\
\hline Eat & & & \\
\end{tabular}

Each value is expressed as mean $\pm \mathrm{SD}$ of the gated cells.

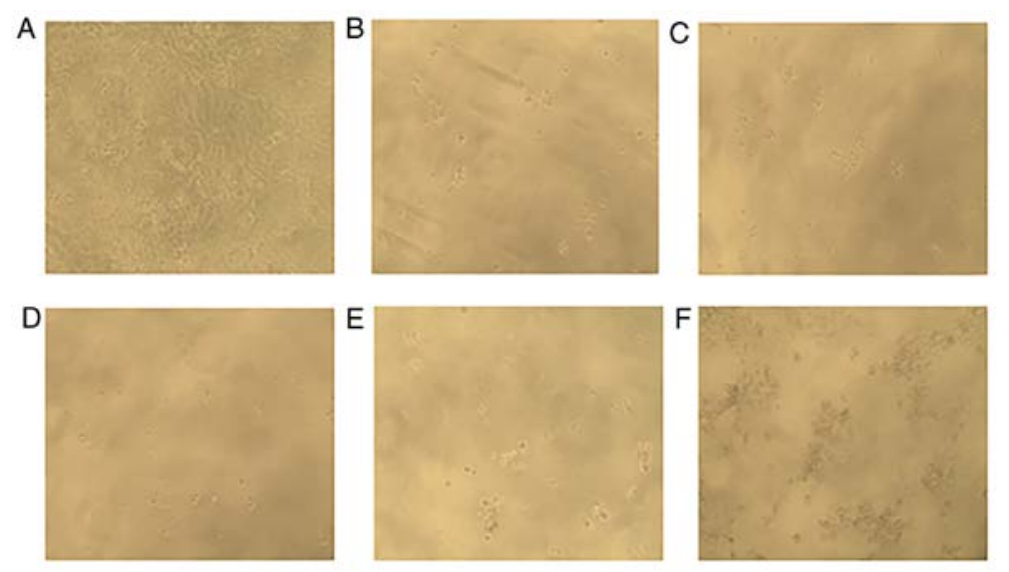

Figure 3. Morphology of BxPC-3 cells (A) following treatment with CDK inhibitor dinaciclib (B) SRC targeting TKI dasatinib (C) cytotoxic agent gemcitabine (D) the irreversible pan-HER TKI afatinib (E) and the STAT3 inhibitor stattic (F) CDK, cyclin-dependent kinase; TKI, tyrosine kinase inhibitor; HER, human epidermal growth factor receptor; STAT3, signal transducer and activator of transcription 3.

positive control (i.e., no treatment, $10 \%$ FBS medium only) most drugs inhibited the migration of HPCCLs with SRC targeting
TKI dasatinib, and the CDK inhibitor dinaciclib and the irreversible pan-HER TKI afatinib being most effective (Fig. 5A and B). 
A

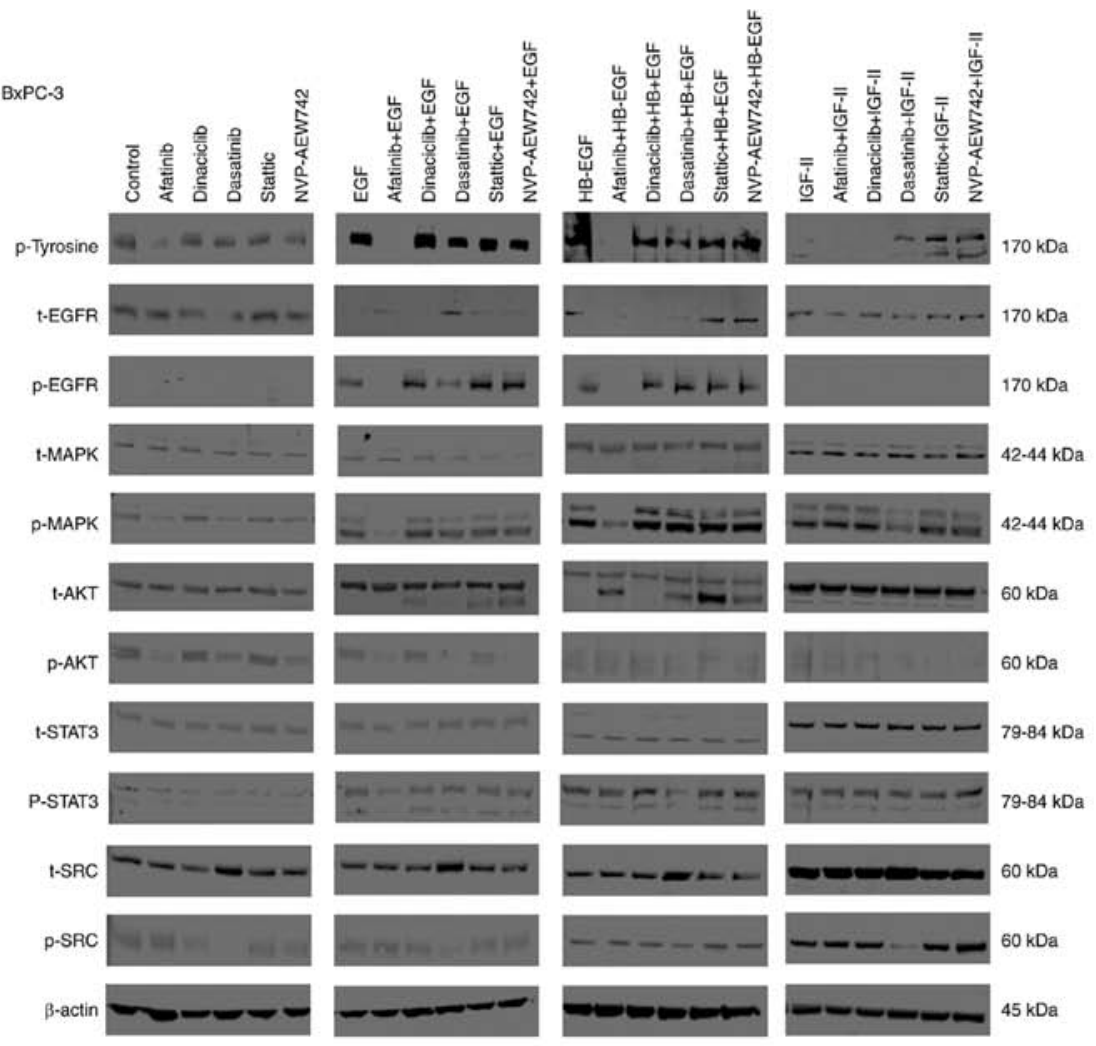

B

Capan-1
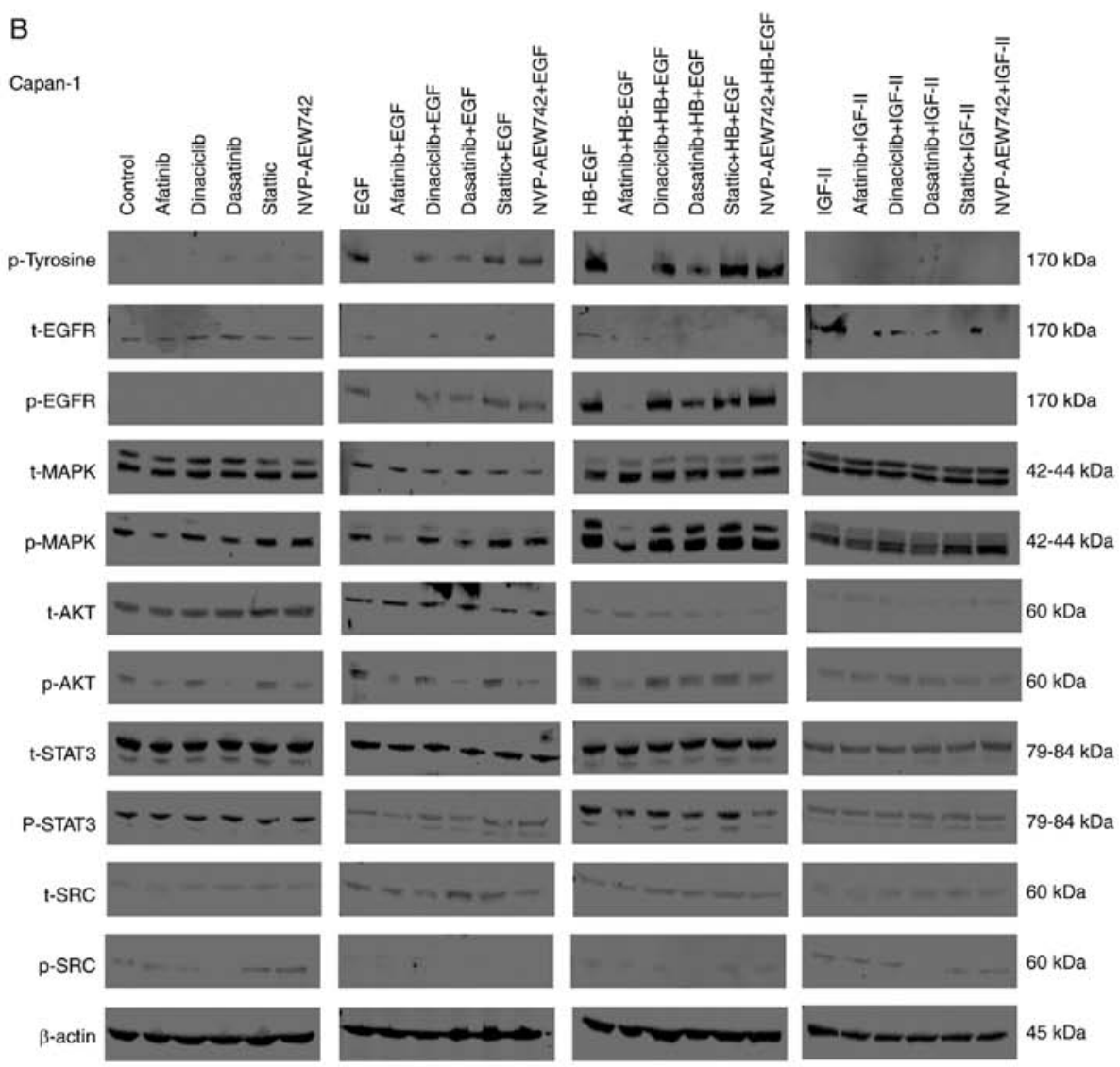

Figure 4. Effect of afatinib, dinaciclib, dasatinib, stattic and NVP-AEW742 with or without ligands (EGF, HB-EGF, IGF-II) on the phosphorylation of EGFR and downstream cell signaling molecules including MAPK, AKT, STAT3, SRC and IGF-IR in BxPC-3 (A) and Capan-1 (B) cells. The cells were cultured in $10 \%$ FBS RPMI-1640 medium to near confluency. Cells were washed once with 0.5\% FBS RPMI-1640 medium and incubated with selected agents (400 nM) for $1 \mathrm{~h}$ and then stimulated with $40 \mathrm{nM}$ ligands (EGF, HB-EGF and IGF-II) for $15 \mathrm{~min}$. Cells were then lysed, separated using SDS-PAGE, transferred onto PDVF membranes, probed with the antibodies of interest and visualized using LI-COR software. EGF, epidermal growth factor; HB-EGF, heparin-binding EGF-like growth factor; IGF-II, insulin-like growth factor II; EGFR, epidermal growth factor receptor; MAPK, mitogen-activated protein kinase; AKT, protein kinase B or PKB; STAT3, signal transducer and activator of transcription 3; SRC, proto-oncogene tyrosine kinase SRC; IGF-IR, insulin-like growth fact) or 1 receptor. 
Table IV. Combination index (CI) values of dinaciclib plus afatinib, dasatinib plus afatinib and dasatinib plus gemcitabine in human pancreatic cancer cell lines.

\begin{tabular}{lccc}
\hline Cell lines & $\begin{array}{c}\text { Dinaciclib + afatinib } \\
\text { combination index (effect) }\end{array}$ & $\begin{array}{c}\text { Afatinib + dasatinib } \\
\text { combination index (effect) }\end{array}$ & $\begin{array}{c}\text { Dasatinib + gemcitabine } \\
\text { combination index (effect) }\end{array}$ \\
\hline BxPC-3 & 1.32 (slight antagonism) & 0.97 (nearly additive) & 0.85 (moderate synergism) \\
Capan-1 & 1.85 (antagonism) & 0.39 (synergism) & 0.35 (synergism) \\
FA-6 & 1.60 (antagonism) & 0.53 (synergism) & 0.66 (synergism) \\
Mia-Paca2 & 1.66 (antagonism) & 0.58 (synergism) & 0.85 (moderate synergism) \\
\hline
\end{tabular}

\section{Discussion}

Despite major advances in the early diagnosis and treatment of solid tumors in the past three decades, pancreatic cancer remains as one of the most aggressive and deadliest forms of cancer. By 2030, it is predicted to become the second leading cause of cancer-related deaths after lung cancer (31). Due to its heterogenous nature, its retroperitoneal location, non-specific symptoms and lack of screening methods, the overwhelming majority of pancreatic cancer patients are diagnosed at an advanced stage of the disease at the time of presentation (32). To date, of the HER inhibitors, only the EGFR-specific tyrosine kinase inhibitor (TKI), erlotinib has gained the FDA approval for the targeted therapy of locally advanced, unresectable or metastatic pancreatic cancer in combination with the cytotoxic agent gemcitabine (14). However, the majority of pancreatic cancer patients have either primary resistance, or develop seondary resistance following a short course of erlotinib. As a result, the duration of response can be short in many patients $(7,30)$. Therefore, there is an urgent need to discover more effective therapeutic interventions for patients diagnosed with different stages of pancreatic cancer (7).

We previously demonstrated that of the pan HER family blocker, afatinib was more effective than erlotinib in inhibiting the growth of human pancreatic cancer cells (27). We also reported that treatment with afatinib in combination the insulin-like growth factor 1 receptor (IGF-IR) inhibitor NVP-AEW541 resulted in synergistic growth inhibition of pancreatic cancer cells (15). Due to the heterogeneous nature of pancreatic cancer, in this study we investigated the growth response of human pancreatic cancer cell lines (HPCCLs), established from patients at different stages of the disease, to the treatment with agents targeting different cyclin-dependent kinases (CDKs), various growth factor receptors and cell signaling molecules.

Of all the agents examined, the CDK1/2/5/9 inhibitor, dinaciclib was the most potent agent and inhibited the proliferation of all seven primary and metastatic HPCCLs with $\mathrm{IC}_{50}$ values of $\leq 10 \mathrm{nM}$. Pre-clinical testing of dinaciclib exhibited an acceptable toxicity profile and effective inhibition in mouse models and it was found to be safe and well tolerated in phase I trials $(33,34)$. The second most effective agent with anti-proliferative activity was the SRC/c-kit/Abl inhibitor dasatinib. It inhibited the growth of all seven primary and metastatic HPCCLs with $\mathrm{IC}_{50}$ of $\leq 258 \mathrm{nM}$ ). However, the most sensitive cell line to growth inbition by dasatinib were Bx-PC3 and Mia-PaCa-2, which were established from two primary tumors and with $\mathrm{IC}_{50}$ values of 70 and $80 \mathrm{nM}$, respectively. The third most effective agent was the STAT3 inhibitor stattic which inhibited the growth of all HPCCLs with $\mathrm{IC}_{50}$ of $\leq 2 \mu \mathrm{M}$. The pan-HER family blocker also inhibited the growth of all seven HPCCLs with $\mathrm{IC}_{50}$ values $\leq 2.95 \mu \mathrm{M}$ ). However, the most sensitivite cell lines to treatment with afatinib were the EGFR, HER 2 and HER3-positive BxPC-3 and CF-PAC1 cells whereas the reversible EGFR TKI erlotinib was only effective in BxPC-3, CF-PAC1 and Hs766T cells. We found a statistically significant association between HER3 expression and their response to treatment with TKIs targeting HER family members. In another study, Frolov and colleagues suggested that the higher sensitivity of HER3-positive cell lines to treatment with pan-HER TKIs could be due to blockade of HER-3 transactivation via EGFR therefore inhibiting PI3K/AKT signaling pathways (35). Other studies have also supported the association between the expression level of HER3 and the sensitivity of pancreatic cancer cell lines to treatment with erlotinib $(35,36)$. Although our panel of cell lines was moderately positive for IGF-IR and showed moderate sensitivity to agents targeting IGF-IR and fibroblast growth factor receptor (FGFR), some statistically significant associations were found between IGF-IR expression and their response to treatment with HER family TKIs as well as HER2 expression and treatment with ALK/IGF-IR/InsR inhibitor ceritinib and FGFR inhibitor AZD4547. Both IGF-IR and FGFR-mediated signaling pathways have been found to participate in the resistance to anti-HER targeted therapy $(15,37,38)$. Moreover, we and other researchers have shown that the co-targeting of IGF-IR and HER family members results in synergistic growth inhibition of human pancreatic cancer cells $(15,39)$.

The synchronous activation of bypass pathways via receptor tyrosine kinases (RTKs) including c-MET and ALK7 has been shown to induce resistance to current treatments and have emerged as important therapeutic targets for pancreatic cancer treatments. The expression level of both these receptors in our panel of cell lines was moderate. While the growth of all seven HPCCLs were inhibited by the dual c-MET/ALK TKI crizotinib (i.e., $\mathrm{IC}_{50}$ values $\leq 3.3 \mu \mathrm{M}$ ), none of the cell lines were sensitive to treatment with the c-MET-specific TKI, capmatinib (i.e., $\mathrm{IC}_{50}$ values $>10 \mu \mathrm{M}$ ). However, a significant association was found between c-MET and ALK-7 expression and their response to treatment with the STAT3 inhibitor stattic. STAT3 lies at the convergence of multiple oncogenic signaling pathways stimulated by upstream activated receptors such as c-MET and ALK $(19,40)$. A study reported that hyperactivated 
Table V. Linear regression analysis of the expression of various receptors against the sensitivity of human pancreatic cancer cell lines to treatment with various TKIs, CDK inhibitors, STAT3 inhibitor and a cytotoxic agent.

\begin{tabular}{|c|c|c|c|c|c|c|}
\hline $\begin{array}{l}\text { Drugs/cell } \\
\text { surface markers }\end{array}$ & $\begin{array}{l}\text { EGFR R } \\
\text { (P-value) }\end{array}$ & $\begin{array}{l}\text { HER2 R } \\
\text { (P-value) }\end{array}$ & $\begin{array}{l}\text { HER3 R } 2 \\
\text { (P-value) }\end{array}$ & $\begin{array}{l}\text { IGF-IR R }^{2} \\
\text { (P-value) }\end{array}$ & $\begin{array}{c}\text { C-MET R } 2 \\
\text { (P-value) }\end{array}$ & $\begin{array}{l}\text { ALK7 R } \\
\text { (P-value) }\end{array}$ \\
\hline Palbociclib & $0.004(0.895)$ & $0.345(0.165)$ & $0.046(0.646)$ & $0.001(0.940)$ & $0.091(0.511)$ & $0.125(0.437)$ \\
\hline Crizotinib & $0.203(0.310)$ & $0.185(0.336)$ & $0.230(0.276)$ & $0.017(0.779)$ & $0.158(0.377)$ & $0.029(0.715)$ \\
\hline Ceritinib & $0.001(0.948)$ & $0.698(0.019)$ & $0.496(0.077)$ & $0.038(0.674)$ & $0.031(0.704)$ & $0.002(0.916)$ \\
\hline Brigatinib & $0.184(0.692)$ & $0.180(0.343)$ & $0.132(0.424)$ & $0.069(0.569)$ & $0.031(0.705)$ & $0.021(0.756)$ \\
\hline Erlotinib & $0.018(0.772)$ & $0.204(0.309)$ & $0.830(0.004)$ & $0.608(0.039)$ & $0.449(0.100)$ & $0.371(0.147)$ \\
\hline Afatinib & $0.000(0.965)$ & $0.188(0.331)$ & $0.599(0.041)$ & $0.672(0.024)$ & $0.386(0.137)$ & $0.248(0.256)$ \\
\hline Gemcitabine & $0.197(0.318)$ & $0.087(0.522)$ & $0.021(0.785)$ & $0.005(0.882)$ & $0.006(0.865)$ & $0.026(0.732)$ \\
\hline Dasatinib & $0.231(0.275)$ & $0.034(0.691)$ & $0.105(0.478)$ & $0.007(0.854)$ & $0.268(0.234)$ & $0.020(0.763)$ \\
\hline Linsitinib & $0.114(0.459)$ & $0.133(0.421)$ & $0.062(0.589)$ & $0.088(0.519)$ & $0.038(0.674)$ & $0.000(0.972)$ \\
\hline Stattic & $0.232(0.274)$ & $0.008(0.845)$ & $0.483(0.083)$ & $0.412(0.120)$ & $0.809(0.006)$ & $0.682(0.022)$ \\
\hline Crenolanib & $0.034(0.694)$ & $0.236(0.269)$ & $0.010(0.828)$ & $0.189(0.329)$ & $0.232(0.274)$ & $0.000(0.983)$ \\
\hline Bosutinib & $0.003(0.903)$ & $0.020(0.763)$ & $0.355(0.158)$ & $0.074(0.555)$ & $0.747(0.012)$ & $0.397(0.129)$ \\
\hline AZD4547 & $0.001(0.959)$ & $0.751(0.012)$ & $0.063(0.587)$ & $0.053(0.620)$ & $0.054(0.616)$ & $0.040(0.667)$ \\
\hline Ponatinib & $0.261(0.241)$ & $0.041(0.663)$ & $0.186(0.334)$ & $0.091(0.512)$ & $0.066(0.577)$ & $0.037(0.681)$ \\
\hline
\end{tabular}

SPSS software was used to determine the significance and $\mathrm{R}^{2}$ value using linear regression analysis where the expression of cell surface marker was independent variable and $\mathrm{IC}_{50}$ value of the drug was the dependent variable. A R2 value closer to 1 indicated reliability of the data whereas P-value of $<0.05$ was considered statistically significant (printed in bold). TKIs, tyrosine kinase inhibitors, CDK, cyclin-dependent kinase; STAT3, signal transducer and activator of transcription 3; $\mathrm{IC}_{50}$, half maximal inhibitory concentration; EGFR, epidermal growth factor receptor; HER, human epidermal growth factor receptor; IGF-IR, insulin-like growth factor 1 receptor; ALK7, anaplastic lymphoma kinase 7.

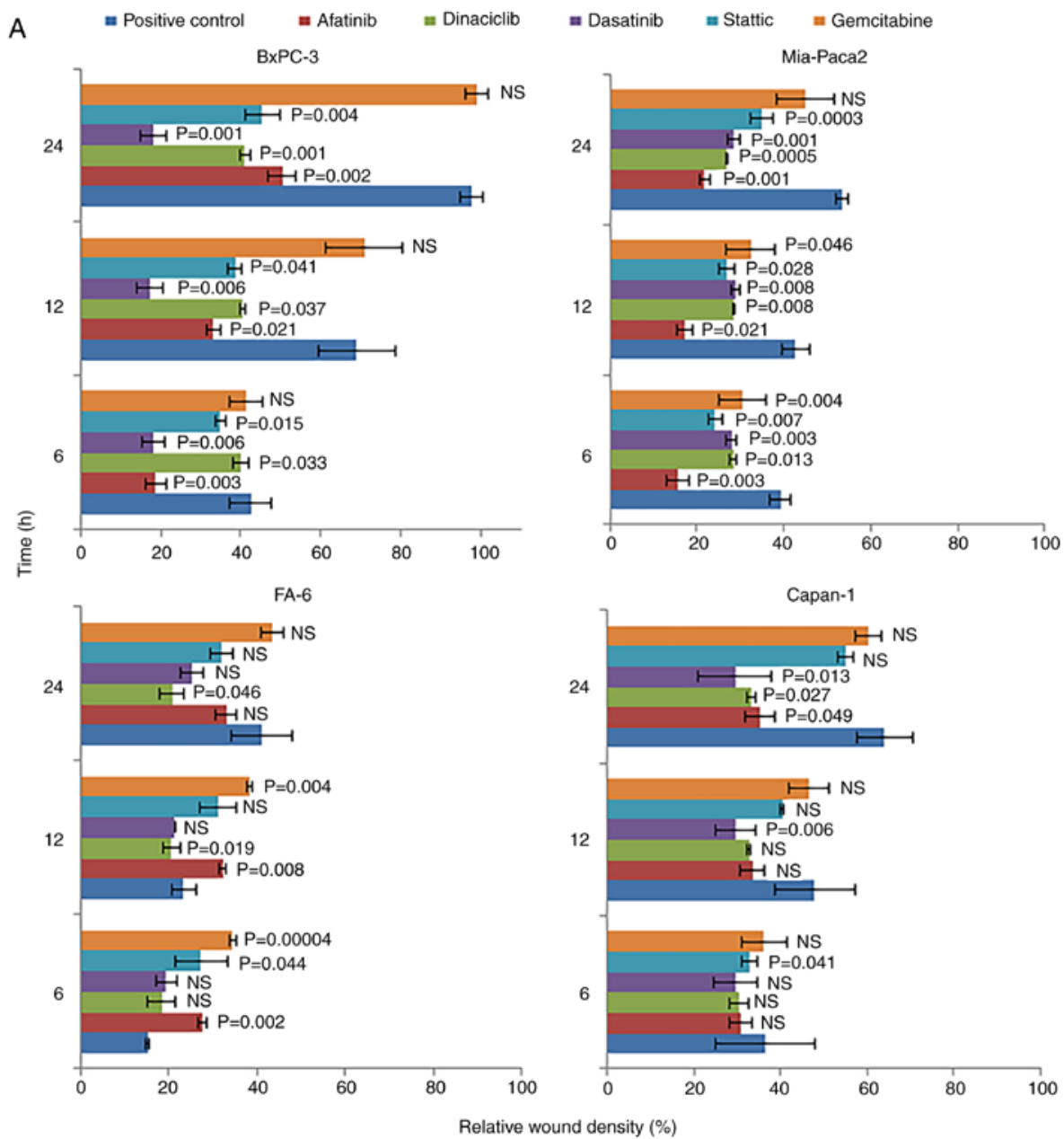

Figure 5. Continued. 
B

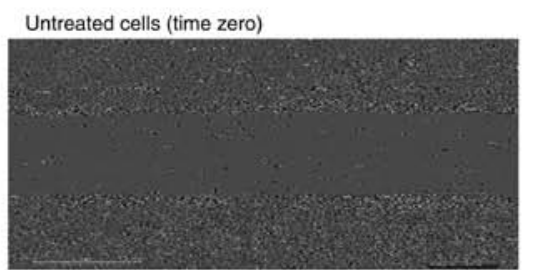

Afatinib (time zero)

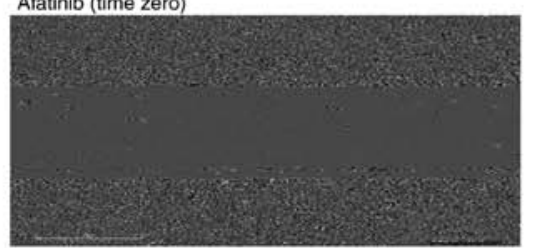

Dinaciclib (time zero)

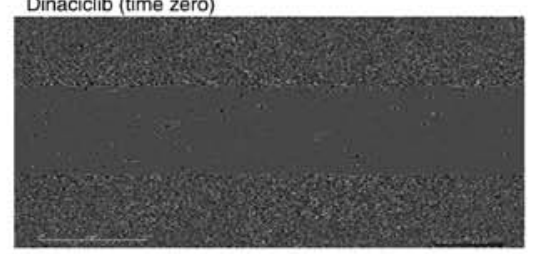

Dasatinib (time zero)

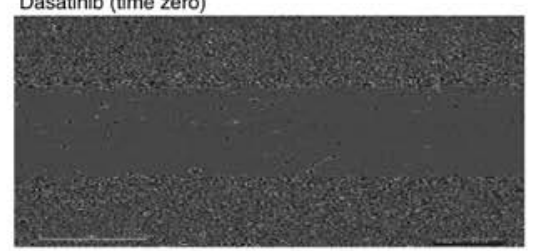

Stattic (time zero)

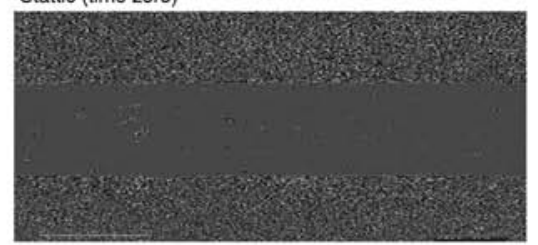

Gemcitabine (time zero)

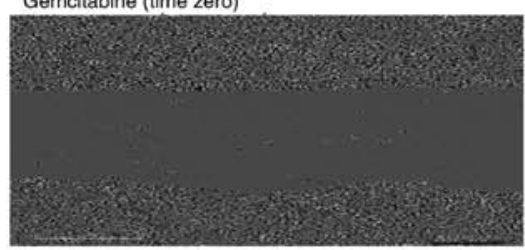

Control (untreated cells at $24 \mathrm{~h}$ )

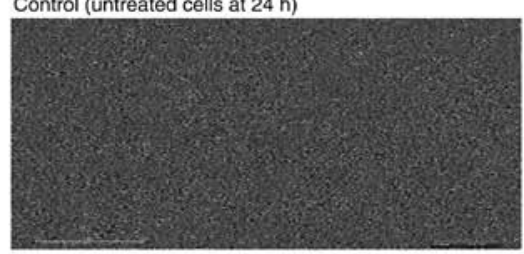

Afatinib (at $24 \mathrm{~h}$ )

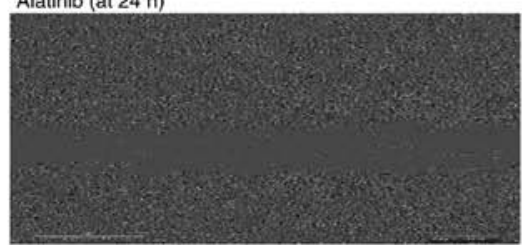

Dinaciclib (at $24 \mathrm{~h}$ )

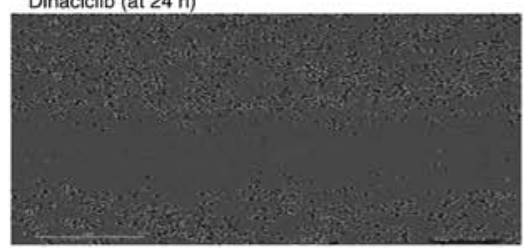

Dasatinib (at 24 h)

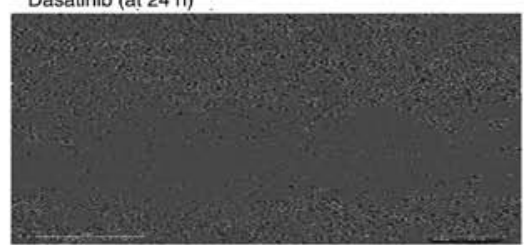

Stattic (at $24 \mathrm{~h}$ )

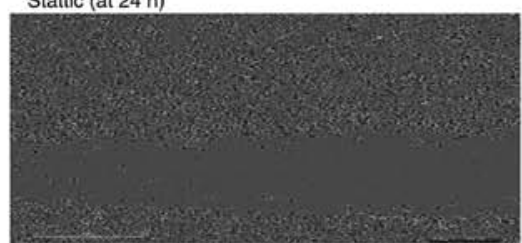

Gemcitabine (at $24 \mathrm{~h}$ )

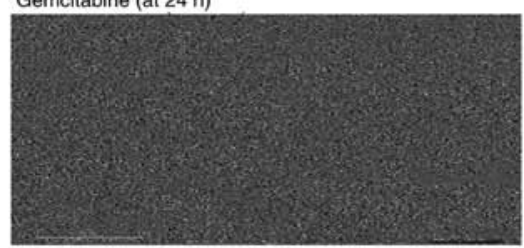

Figure 5. (A) Effect of selected agents on the migration of human pancreatic cancer cell lines at different time intervals. P<0.05 was considered significant; NS, not significant. (B) Effect of various agents on the migration of BxPC-3 cells at 24 post treatment using scratch wound healing experiment.

STAT3 signaling in non-small cell lung cancer (NSCLC) was induced by the activation of MET (41). In addition, a significant association was found between c-MET expression and $\mathrm{Src} / \mathrm{Abl}$ inhibitor bosutinib. The SRC and Abl are some of the intracellular effector molecules recruited following auto-phosphorylation of docking site of activated c-MET (40). Overexpression and activation of the c-MET receptor have been shown to be involved in SRC kinase activation (42).

Cell cycle distribution analysis revealed that the treatment of HPCCLs with afatinib, dasatinib, dinaciclib, stattic and gemcitabine increased the population of cells in sub-G1 with concomitant decrease in the G1 phase. Afatinib treatment also increased cells in the $\mathrm{S}$ and $\mathrm{G} 2 / \mathrm{M}$ phase in most of the cell lines and similar results were reported following the treatment of nasopharyngeal carcinomas with afatinib (43). Dinaciclib treatment caused S-phase arrest in most of the cell lines which is consistent with the blockage of CDK2, one of the targets of dinaciclib (44). Treatment with dasatinib arrested cells in the $\mathrm{S}$ and $\mathrm{G} 2 / \mathrm{M}$ phase which is consistent with a study where increasing the dasatinib concentration from $0.5-1.0 \mu \mathrm{M}$ increased the percentage of BxPC-3 cells in the S-phase (21). Treatment with the cytotoxic agent gemcitabine increased cells in S-phase consistent with the inhibition of DNA replication (45). Treatment with afatinib, dastainib and stattic inhibited the phophorylation of EGFR, SRC and STAT3, respectively and the migration of four human pancreatic cancer cell lines, established from patients with either a primary tumor or a meastatic tumor. Our results suggest that treatment with these agents result in inhibition of two hallmarks of cancer which are tumour cell proliferation and migration.

Next, we investigated the combinational potential of most effective drugs on four HPCCLs. We found that treatment with a combination of SRC targeting TKI dasatinib with the pan-HER TKI afatinib resulted in synergistic growth 
inhibition of all four HPCCLs examined. Treatment with the combination of dasatinib with gemcitabine also resulted in synergistic growth inhibition of four HPCCLs, including those established from patients with a primary pancreatic tumor (e.g., Bx-PC-3) or liver metastasis (e.g., Capan-1). Consistent with the results of a present study, the latter combination has been reported to have synergistic effect in two other HPCCLs $(46,47)$. Although, dasatinib and gemcitabine combination has been shown to promote stable disease and to induce a partial response in patients with pancreatic cancer (48), it failed to improve patient survival in a phase II trial setting due to increased toxicity of such a combination (49). This combination is currently being used in a phase II trial in pancreatic cancer patients (ClinicalTrials.gov Identifier: NCT01234935). The triple combination of SRC inhibitor (dasatinib), EGFR inhibitor (erlotinib) and gemcitabine demonstrated a synergistic antitumor effect in pancreatic ductal adenocarcinoma (PDAC) as well as encouraging preliminary activity in patients with advanced pancreatic cancer $(50,51)$. However, when afatinib was used in combination with the CDK1/2/5/9 inhibitor, dinaciclib, such a combination had agonistic effect in all cell lines examined. This highlights the importance of selecting the appropriate partner when such drugs are used in combination.

In conclusion, we demonstrated that of various targeting agents employed in our study, the CDK inhibitor dinaciclib, the irreversible pan-HER TKI afatinib, and the SRC targeting TKI dasatinib were most effective at inhibiting the proliferation and migration of HPCCLs, established from both a primary pancreatic cancer and from a metastatic pancreatic cancer. The combination of dasatinib with afatinib and dasatinib with gemcitabine led to synergistic growth inhibition in pancreatic cancer cell lines. Our results support the need for further investigation of the therapeutic potential of these combinations in the treatment of pancreatic cancer.

\section{Acknowledgements}

We would like to thank Dr Soozana Puvanenthiran, School of Life Science, Pharmacy and Chemistry, Kingston University London, Kingston, UK for her help with preparation with various figures.

\section{Funding}

This study was supported by the Kingston University as part of a self-funded $\mathrm{PhD}$ project at the Kingston University London, UK.

\section{Availability of data and material}

The datasets used and/or analyzed during the current study are available from the corresponding author on reasonable request.

\section{Authors' contributions}

TK performed the experiments and conducted data analysis as part of her PhD project. HM conceived the original research idea, read, and revised the manuscript. TK and HM wrote the manuscript. SK and NI carried out data analysis. AMS,
AGD and SM were the other PhD supervisors on this study and thus were also involved in all aspects of the experiments, data analysis and writing. All authors have read and approved the study.

\section{Ethics approval and consent to participate}

Not applicable.

\section{Patient consent for publication}

Not applicable.

\section{Competing interests}

The authors declare that they have no competing interests.

\section{References}

1. Bray F, Ferlay J, Soerjomataram I, Siegel RL, Torre LA and Jemal A: Global cancer statistics 2018: GLOBOCAN estimates of incidence and mortality worldwide for 36 cancers in 185 countries. CA Cancer J Clin 68: 394-424, 2018.

2. Rawla P, Sunkara T and Gaduputi V: Epidemiology of pancreatic cancer: Global trends, etiology and risk factors. World J Oncol 10: 10-27, 2019

3. Siegel RL, Miller KD and Jemal A: Cancer statistics, 2020. CA Cancer J Clin 70: 7-30, 2020.

4. Carreras-Torres R, Johansson M, Gaborieau V, Haycock PC, Wade KH, Relton CL, Martin RM, Davey Smith G and Brennan P: The role of obesity, type 2 diabetes, and metabolic factors in pancreatic cancer: A mendelian randomization study. J Natl Cancer Inst 109: djx012, 2017.

5. Lauby-Secretan B, Scoccianti C, Loomis D, Grosse Y, Bianchini F and Straif K; International Agency for Research on Cancer Handbook Working Group: Body Fatness and Cancer-Viewpoint of the IARC Working Group. N Engl J Med 375: 794-798, 2016.

6. Wolfgang CL, Herman JM, Laheru DA, Klein AP, Erdek MA, Fishman EK and Hruban RH: Recent progress in pancreatic cancer. CA Cancer J Clin 63: 318-348, 2013.

7. Ioannou N, Seddon AM, Dalgleish A, Mackintosh D and Modjtahedi $\mathrm{H}$ : Expression pattern and targeting of HER family members and IGF-IR in pancreatic cancer. Front Biosci (Landmark Ed) 2012. 17: 2698-2724, 2012.

8. Seshacharyulu P, Ponnusamy MP, Haridas D, Jain M, Ganti AK and Batra SK: Targeting the EGFR signaling pathway in cancer therapy. Expert Opin Ther Targets 16: 15-31, 2012.

9. Tebbutt N, Pedersen MW and Johns TG: Targeting the ERBB family in cancer: Couples therapy. Nat Rev Cancer 13: 663-673, 2013.

10. Li Q, Zhang L, Li X, Yan H, Yang L, Li Y, Li T, Wang J and Cao B: The prognostic significance of human epidermal growth factor receptor family protein expression in operable pancreatic cancer: HER1-4 protein expression and prognosis in pancreatic cancer. BMC Cancer 16: 910, 2016.

11. Perini MV, Montagnini AL, Coudry R, Patzina R, Penteado S, Abdo EE, Diniz A, Jukemura J and da Cunha JE: Prognostic significance of epidermal growth factor receptor overexpression in pancreas cancer and nodal metastasis. ANZ J Surg 85: 174-178, 2015.

12. Mahipal A, Mcdonald MJ, Witkiewicz A and Carr BI: Cell membrane and cytoplasmic epidermal growth factor receptor expression in pancreatic ductal adenocarcinoma. Med Oncol 29: 134-139, 2012.

13. Einama T, Ueda S, Tsuda H, Ogasawara K, Hatsuse K, Matsubara O, Todo S and Yamamoto J: Membranous and cytoplasmic expression of epidermal growth factor receptor in metastatic pancreatic ductal adenocarcinoma. Exp Ther Med 3: 931-936, 2012.

14. Moore MJ, Goldstein D, Hamm J, Figer A, Hecht JR, Gallinger S, Au HJ, Murawa P, Walde D, Wolff RA, et al: Erlotinib plus gemcitabine compared with gemcitabine alone in patients with advanced pancreatic cancer: A phase III trial of the National Cancer Institute of Canada clinical trials group. J Clin Oncol 25: 1960-1966, 2007. 
15. Ioannou N, Seddon AM, Dalgleish A, Mackintosh D and Modjtahedi H: Treatment with a combination of the ErbB (HER) family blocker afatinib and the IGF-IR inhibitor, NVP-AEW541 induces synergistic growth inhibition of human pancreatic cancer cells. BMC Cancer 13: 41, 2013.

16. Nones K, Waddell N, Song S, Patch AM, Miller D, Johns A, Wu J, Kassahn KS, Wood D, Bailey P, et al: Genome-wide DNA methylation patterns in pancreatic ductal adenocarcinoma reveal epigeneticderegulation ofSLIT-ROBO,ITGA2andMETsignaling. Int J Cancer 135: 1110-1118, 2014.

17. Zhou W, Jubb AM, Lyle K, Xiao Q, Ong CC, Desai R, Fu L, Gnad F, Song Q, Haverty PM, et al: PAK1 mediates pancreatic cancer cell migration and resistance to MET inhibition. J Pathol 234: 502-513, 2014.

18. Zhu GH, Huang C, Qiu ZJ, Liu J, Zhang ZH, Zhao N, Feng ZZ and Lv XH: Expression and prognostic significance of CD151, c-Met, and integrin alpha3/alpha6 in pancreatic ductal adenocarcinoma. Dig Dis Sci 56: 1090-1098, 2011.

19. Liu C, Yang Z, Li D, Liu Z, Miao X, Yang L, Zou Q and Yuan Y: Overexpression of B2M and loss of ALK7 expression are associated with invasion, metastasis, and poor-prognosis of the pancreatic ductal adenocarcinoma. Cancer Biomark 15: 735-743, 2015.

20. Shields DJ, Murphy EA, Desgrosellier JS, Mielgo A, Lau SK, Barnes LA, Lesperance J, Huang M, Schmedt C, Tarin D, et al: Oncogenic Ras/Src cooperativity in pancreatic neoplasia. Oncogene 30: 2123-2134, 2011.

21. Nagaraj NS, Smith JJ, Revetta F, Washington MK and Merchant NB: Targeted inhibition of SRC kinase signaling attenuates pancreatic tumorigenesis. Mol Cancer Ther 9: 2322-2332, 2010.

22. Morton JP, Karim SA, Graham K, Timpson P, Jamieson N, Athineos D, Doyle B, McKay C, Heung MY, Oien KA, et al: Dasatinib inhibits the development of metastases in a mouse model of pancreatic ductal adenocarcinoma. Gastroenterology 139: 292-303, 2010.

23. Chee CE, Krishnamurthi S, Nock CJ, Meropol NJ, Gibbons J, Fu P, Bokar J, Teston L, O'Brien T, Gudena V, et al: Phase II study of dasatinib (BMS-354825) in patients with metastatic adenocarcinoma of the pancreas. Oncologist 18: 1091-1092, 2013.

24. Cros J, Raffenne J, Couvelard A and Poté N: Tumor heterogeneity in pancreatic adenocarcinoma. Pathobiology 85: 64-71, 2018.

25. Yao W, Maitra A and Ying H: Recent insights into the biology of pancreatic cancer. EBioMedicine 53: 102655, 2020.

26. Haeberle L, Steiger K, Schlitter AM, Safi SA, Knoefel WT, Erkan M and Esposito I: Stromal heterogeneity in pancreatic cancer and chronic pancreatitis. Pancreatology: May 12, 2018 (Epub ahead of print).

27. Ioannou N, Dalgleish AG, Seddon AM, Mackintosh D, Guertler U, Solca F and Modjtahedi H: Anti-tumour activity of afatinib, an irreversible ErbB family blocker, in human pancreatic tumour cells. Br J Cancer 105: 1554-1562, 2011.

28. Stanley A, Ashrafi GH, Seddon AM and Modjtahedi H: Synergistic effects of various Her inhibitors in combination with IGF-1R, C-MET and Src targeting agents in breast cancer cell lines. Sci Rep 7: 3964, 2017.

29. Cunningham MP, Thomas H, Fan $\mathrm{Z}$ and Modjtahedi $\mathrm{H}$ : Responses of human colorectal tumor cells to treatment with the anti-epidermal growth factor receptor monoclonal antibody ICR62 used alone and in combination with the EGFR tyrosine kinase inhibitor gefitinib. Cancer Res 66: 7708-7715, 2006.

30. Ioannou N, Seddon AM, Dalgleish A, Mackintosh D, Solca F and Modjtahedi H: Acquired resistance of pancreatic cancer cells to treatment with gemcitabine and HER-inhibitors is accompanied by increased sensitivity to STAT3 inhibition. Int J Oncol 48 : 908-918, 2016

31. Rahib L, Smith BD, Aizenberg R, Rosenzweig AB, Fleshman JM and Matrisian LM: Projecting cancer incidence and deaths to 2030: The unexpected burden of thyroid, liver, and pancreas cancers in the United States. Cancer Res 74: 2913-2921, 2014.

32. Adel N: Current treatment landscape and emerging therapies for pancreatic cancer. Am J Manag Care 25 (1 Suppl): S3-S10, 2019.

33. Parry D, Guzi T, Shanahan F, Davis N, Prabhavalkar D Wiswell D, Seghezzi W, Paruch K, Dwyer MP, Doll R, et al: Dinaciclib (SCH 727965), a novel and potent cyclin-dependent kinase inhibitor. Mol Cancer Ther 9: 2344-2353, 2010.

34. Nemunaitis JJ, Small KA, Kirschmeier P, Zhang D, Zhu Y, Jou YM, Statkevich P, Yao SL and Bannerji R: A first-in-human, phase 1, dose-escalation study of dinaciclib, a novel cyclin-dependent kinase inhibitor, administered weekly in subjects with advanced malignancies. J Transl Med 11: 259, 2013.
35. Frolov A, Schuller K, Tzeng CW, Cannon EE, Ku BC, Howard JH, Vickers SM, Heslin MJ, Buchsbaum DJ and Arnoletti JP: ErbB3 expression and dimerization with EGFR influence pancreatic cancer cell sensitivity to erlotinib. Cancer Biol Ther 6: 548-554, 2007.

36. Buck E, Eyzaguirre A, Haley JD, Gibson NW, Cagnoni P and Iwata KK: Inactivation of Akt by the epidermal growth factor receptor inhibitor erlotinib is mediated by HER-3 in pancreatic and colorectal tumor cell lines and contributes to erlotinib sensitivity. Mol Cancer Ther 5: 2051-2059, 2006.

37. Ware KE, Marshall ME, Heasley LR, Marek L, Hinz TK, Hercule P, Helfrich BA, Doebele RC and Heasley LE: Rapidly acquired resistance to EGFR tyrosine kinase inhibitors in NSCLC cell lines through de-repression of FGFR2 and FGFR3 expression. PLoS One 5: e14117, 2010.

38. Azuma K, Kawahara A, Sonoda K, Nakashima K, Tashiro K, Watari K, Izumi H, Kage M, Kuwano M, Ono M and Hoshino T: FGFR1 activation is an escape mechanism in human lung cancer cells resistant to afatinib, a pan-EGFR family kinase inhibitor. Oncotarget 5: 5908-5919, 2014.

39. Urtasun N, Vidal-Pla A, Pérez-Torras S and Mazo A: Human pancreatic cancer stem cells are sensitive to dual inhibition of IGF-IR and ErbB receptors. BMC Cancer 15: 223, 2015.

40. Al-U'datt DGF, Al-Husein BAA and Qasaimeh GR: A mini-review of c-Met as a potential therapeutic target in melanoma. Biomed Pharmacother 88: 194-202, 2017.

41. Bian C, Liu Z, Li D and Zhen L: PI3K/AKT inhibition induces compensatory activation of the MET/STAT3 pathway in non-small cell lung cancer. Oncol Lett 15: 9655-9662, 2018

42. Rahimi N, Hung W, Tremblay E, Saulnier R and Elliott B: c-Src kinase activity is required for hepatocyte growth factor-induced motility and anchorage-independent growth of mammary carcinoma cells. J Biol Chem 273: 33714-33721, 1998.

43. Xue C, Tian Y, Zhang J, Zhao Y, Zhan J, Fang W and Zhang L: In vitro and in vivo efficacy of afatinib as a single agent or in combination with gemcitabine for the treatment of nasopharyngeal carcinoma. Drug Des Devel Ther 10: 1299-1306, 2016.

44. Garcia-Reyes B, Kretz AL, Ruff JP, von Karstedt S, Hillenbrand A, Knippschild U, Henne-Bruns D and Lemke J: The emerging role of cyclin-dependent kinases (CDKs) in pancreatic ductal adenocarcinoma. Int J Mol Sci 19: 3219, 2018.

45. Miao X, Koch G, Ait-Oudhia S, Straubinger RM and Jusko WJ: Pharmacodynamic modeling of cell cycle effects for gemcitabine and trabectedin combinations in pancreatic cancer cells. Front Pharmacol 7: 421, 2016.

46. Duong HQ, Yi YW, Kang HJ, Bae I, Jang YJ, Kwak SJ and Seong YS: Combination of dasatinib and gemcitabine reduces the ALDH1A1 expression and the proliferation of gemcitabine-resistant pancreatic cancer MIA PaCa- 2 cells. Int J Oncol 44: 2132-2138, 2014

47. Ma L, Wei J, Su GH and Lin J: Dasatinib can enhance paclitaxel and gemcitabine inhibitory activity in human pancreatic cancer cells. Cancer Biol Ther 20: 855-865, 2019.

48. Hong DS, Choe JH, Naing A, Wheler JJ, Falchook GS, Piha-Paul S, Moulder SL, George GC, Choe JM, Strauss LC, et al: A phase 1 study of gemcitabine combined with dasatinib in patients with advanced solid tumors. Invest New Drugs 31: 918-926, 2013.

49. Evans TRJ, Van Cutsem E, Moore MJ, Bazin IS, Rosemurgy A, Bodoky G, Deplanque G, Harrison M, Melichar B, Pezet D, et al: Phase 2 placebo-controlled, double-blind trial of dasatinib added to gemcitabine for patients with locally-advanced pancreatic cancer. Ann Oncol 28: 354-361, 2017.

50. Cardin DB, Goff LW, Chan E, Whisenant JG, Dan Ayers G, Takebe N, Arlinghaus LR, Yankeelov TE, Berlin J and Merchant N: Dual Src and EGFR inhibition in combination with gemcitabine in advanced pancreatic cancer: Phase I results: A phase I clinical trial. Invest New Drugs 36: 442-450, 2018.

51. Nagaraj NS, Washington MK and Merchant NB: Combined blockade of Src kinase and epidermal growth factor receptor with gemcitabine overcomes STAT3-mediated resistance of inhibition of pancreatic tumor growth. Clin Cancer Res 17: 483-493, 2011.

This work is licensed under a Creative Commons Attribution-NonCommercial-NoDerivatives 4.0 International (CC BY-NC-ND 4.0) License. 